\title{
$\mathrm{J}$

\section{Homochiral Metal-Organic Frameworks for Enantioselective Separations in Liquid Chromatography}

M. Nieves Corella-Ochoa, ${ }^{\dagger}$ Jesús B. Tapia, ${ }^{\ddagger}$ Heather N. Rubin, ${ }^{\dagger}$ Vanesa Lillo, ${ }^{\dagger}$ Jesús González-Cobos, ${ }^{\dagger}$ José Luis Núñez-Rico, ${ }^{\dagger}$ Salvador R.G. Balestra, ${ }^{\| \odot}$ Neyvis Almora-Barrios, ${ }^{\perp}{ }^{\circledR 0}$ Marina Lledós, ${ }^{\dagger}, \bigcirc$ Arnau Güell-Bara, ${ }^{\dagger}$ Juanjo Cabezas-Giménez, ${ }^{\dagger}, I_{0}$ Eduardo C. Escudero-Adán, ${ }^{\dagger}$

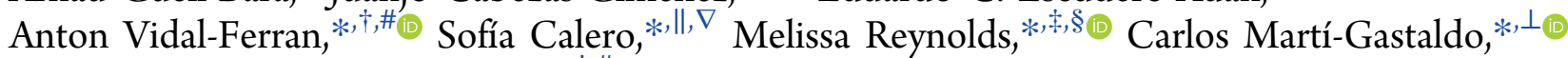
and José Ramón Galán-Mascarós ${ }^{*}$, , \#

${ }^{\dagger}$ Institute of Chemical Research of Catalonia (ICIQ), The Barcelona Institut of Science and Technology (BIST), Av. Països Catalans 16, Tarragona E-43007, Spain

${ }^{*}$ Department of Chemistry, and ${ }^{\S}$ School of Biomedical Engineering, Colorado State University, Fort Collins, Colorado 80523, United States

"Departament of Physical, Chemical and Natural Systems, Universidad Pablo de Olavide, Ctra. Utrera km 1, Sevilla 41013, Spain ${ }^{\perp}$ Instituto de Ciencia Molecular, Universidad de Valencia, Calle Catedrático José Beltrán 2, Paterna 46980, Spain

\#ICREA, Passeig Lluís Companys, 23, Barcelona E-08010, Spain

${ }^{\nabla}$ Department of Applied Physics, Eindhoven University of Technology, Eindhoven $5600 \mathrm{MB}$, The Netherlands

"Departament de Química Física i Inorgànica, Universitat Rovira i Virgili, Marcel.lí Domingo s/n, Tarragona E-43007, Spain

Supporting Information

ABSTRACT: Selective separation of enantiomers is a substantial challenge for the pharmaceutical industry. Chromatography on chiral stationary phases is the standard method, but at a very high cost for industrial-scale purification due to the high cost of the chiral stationary phases. Typically, these materials are poorly robust, expensive to manufacture, and often too specific for a single desired substrate, lacking desirable versatility across different chiral analytes. Here, we disclose a porous, robust homochiral metal-organic framework (MOF), TAMOF-1, built from copper(II) and an affordable linker prepared from natural L-histidine. TAMOF-1 has shown to be able to separate a variety of model racemic

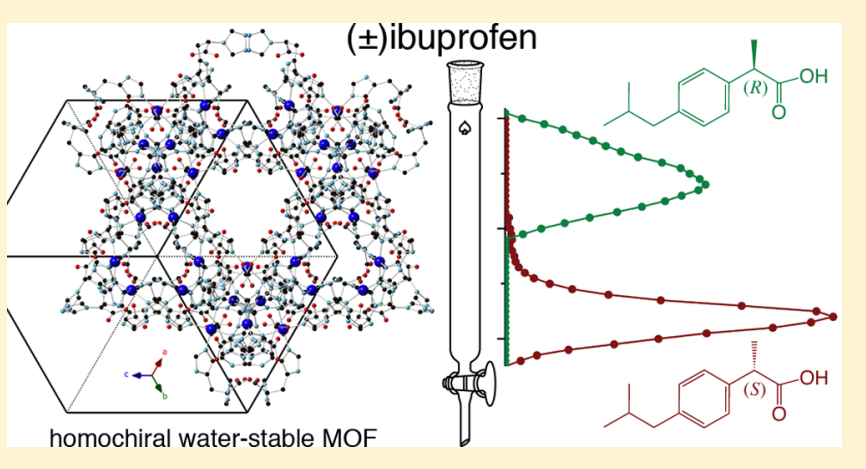
mixtures, including drugs, in a wide range of solvents of different polarity, outperforming several commercial chiral columns for HPLC separations. Although not exploited in the present article, it is worthy to mention that the preparation of this new material is scalable to the multikilogram scale, opening unprecedented possibilities for low-energy chiral separation at the industrial scale.

\section{INTRODUCTION}

"A metal-organic framework, abbreviated to MOF, is a coordination network with organic ligands containing potential voids." This is the IUPAC definition of MOF, and, in its simplicity, it perfectly describes all of their great potential. The combination of metal centers or clusters, with customizable ligands to construct porous structures, offers unparalleled chemical/structural flexibility to meet the desired target properties in these tailor-made materials. ${ }^{2}$ MOFs have been described as excellent candidates for gas storage, ${ }^{3}$ catalysis, ${ }^{4}$ or drug delivery, ${ }^{5}$ just to name a few of their potential applications.

The possibility of implementing pores of specific size, shape, and chemical function inside crystal structures offers unique opportunities for the development of new molecular materials to target specific separations. In this way, chemical design has led to the development of MOFs for efficient and selective separation of gases, hydrocarbons, or aromatic compounds. ${ }^{6}$ In this context, MOFs (heterogeneous in nature) possess an additional advantage when compared to classic adsorbents, such as zeolites or activated carbons, the easier introduction of chirality into frameworks by incorporation of enantiopure linkers. Engineering chiral MOFs is thus a powerful strategy for the development of new chiral stationary phases (CSPs) capable of separating chiral molecules. Chiral drug molecules require stereoselective syntheses or challenging separations to isolate one single

Received: June 25, 2019

Published: August 20, 2019 

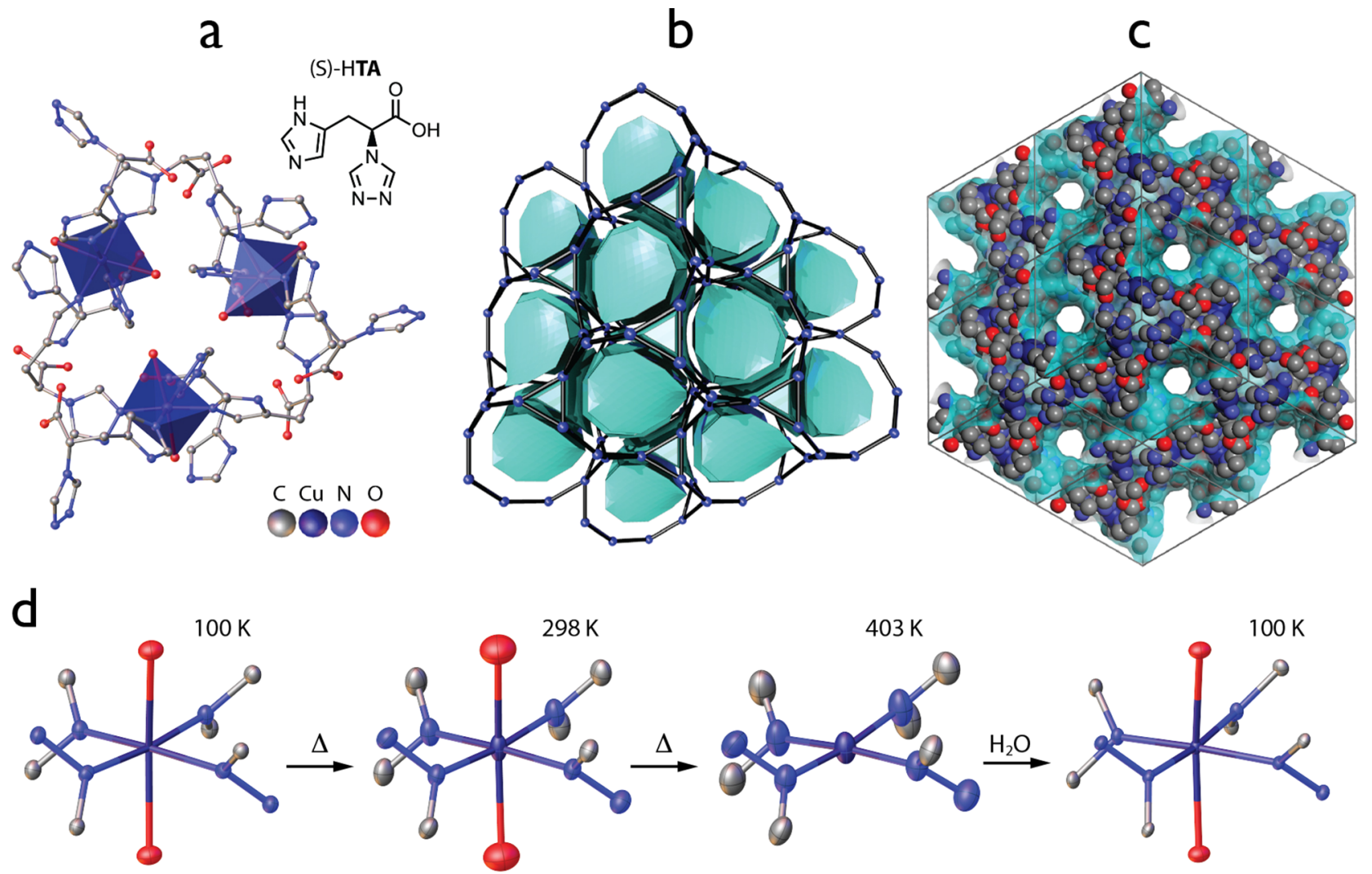

Figure 1. (a) Structure of the linker L-2-deaza-2-(4H-1,2,4-triazol-4-yl)histidine (S-HTA) and projection of the crystal structure of TAMOF-1 on the [111] plane showing the interlinking of $\left\{\mathrm{Cu}(S-\mathrm{TA})_{2}\right\}$ secondary building units by TA linkers in the solid. (b) Natural tiling of polyhedral cages in the $(10,3)$-a connected srs underlying net of TAMOF-1. (c) Overall structure along [111] showing the formation of an open framework with intersected helicoidal channels. Connolly representation of the porosity in the solid phase (pale blue, $1.2 \AA$ A probe radius). (d) Thermal cycle for the coordination geometry of $\mathrm{Cu}^{\mathrm{II}}$ centers. Thermal ellipsoid plots at $3 \AA$ from the metal crystallographic position at 100, 298, and $403 \mathrm{~K}$ (dehydrated state), and again at $100 \mathrm{~K}$ after rehydration by controlled addition of water.

enantiomer. Typically, only one of the enantiomers is biologically beneficial/active, while the other one is inactive or results in undesirable side effects. An easy separation during early stages of the drug discovery process may reduce purification steps and save valuable time and resources necessary to bring a new drug to the market.

Despite the crucial technological relevance of chiral separations for the pharmaceutical industry, it remains an expensive and complex scientific challenge. Current chromatographic technology depends on chiral columns composed by silica beads or polymer composites decorated with organic enantiopure molecules to confer them with chiral recognition and selectivity features. Typically, these materials are poorly robust, expensive to manufacture, and often too specific for a single desired substrate lacking desirable versatility across different chiral analytes. The separation mechanism deals with molecular recognition and strong binding of one of the enantiomers to the receptor sites. Recovery of this enantiomer must be carried out in a second step, and not just by changing the eluent system, as required for conventional chromatography. ${ }^{7}$ Future trends are invested in porous materials with strategically designed target-specific interactions between the support and the molecules to be separated. ${ }^{8}$ The use of MOFs as CSP can circumvent this shortcoming, as separations on these supports are generally based on enantio-differentiation due to the transient formation of diastereoisomeric supramolecular complexes.
Chiral MOFs from enantiopure organic linkers like camphoric acid, tartaric acid, amino acids, or oligopeptides have been reported and used for chiral separation or asymmetric catalysis. ${ }^{9}$ However, these molecules are small and limit the porosity metrics of the resulting frameworks, thereby restricting the size of the guest, mass transfer, analyte concentration, and subsequent interactions with the solid support. Oligopeptides are arguably better fitted for enantiomeric recognition as they can offer higher surface areas and tenable chemical functions by suitable choice of their peptide sequence. ${ }^{10}$ Indeed, some of us recently reported the first example of MOF-based enantioselective separation of drugs by using a copper $3 \mathrm{D} \mathrm{MOF}$ incorporating a tripeptide that enables selective adsorption of ephedrine enantiomers in less than $4 \mathrm{~min}$ in solid-phase extraction. ${ }^{11}$ Nevertheless, this material also suffers from the general problems preventing the implementation of MOFs as CSPs for chromatographic separation. The difficulties found in producing enantiopure MOFs at a large scale from affordable chemicals that maintain high surface areas upon activation, their low chemical stability under the experimental conditions required (multiple solvents and additives), and the challenges associated with their packing (increased pressure) are likely the reasons for which MOFs have not yet been adapted for commercial use.

In the search for alternative strategies toward chiral MOFs that fulfill these requirements, we decided to approach the synthetic modification of proteogenic amino acids (aa's) rather than oligopeptides. The latter are substantially more expensive 
and often display low chemical stability and poor robustness that can result in the uncontrolled collapse of the structure upon solvent removal. ${ }^{12}$ This might prevent accessing higher surface areas for longer peptide sequences. In turn, aa's are inexpensive, readily accessible, and porosity metrics can be tuned by modification of the $C / N$-term positions while avoiding the conformational flexibility intrinsic to peptide bonds. On the basis of previously reported strategies, ${ }^{13}$ we opted to transform $\mathrm{N}$-term amino groups into a $4 \mathrm{H}-1,2,4$-triazole motif. As compared to the starting amino acid, the incorporation of (4H-1,2,4-triazol-4-yl) groups at the $\alpha$ carbon position offers two major advantages. First, porosity may be increased by expansion of the ligand with the five-membered 1,2,4-triazolyl motif. Furthermore, as compared to labile primary amines, this connector was expected to lead to stronger metal-nitrogen coordination bonds for more robust frameworks with excellent thermal and chemical stability.

Herein, we report the first success of this strategy by using the ligand $(S)$-3-(1H-imidazol-5-yl)-2-(4H-1,2,4-triazol-4-yl)propanoic acid ( $S$-HTA, for the molecular structure see Figure 1a) derived from L-histidine. This ligand can be directly reacted with a copper salt in water to produce a crystalline framework. TAMOF-1 (triazole acid metal-organic framework) is an enantiopure MOF with permanent porosity, ca. $1200 \mathrm{~m}^{2} \mathrm{~g}^{-1}$, and good stability in water and organic solvents. It exhibits excellent capabilities for the separation of chiral model compounds and drugs as a chiral stationary phase. As proof of concept, we have achieved the quantitative separation of $( \pm)$-ibuprofen and $( \pm)$-thalidomide, by using a bed of TAMOF-1 to separate a solution containing either drug in two enantiopure aliquots, due to the different retention times for each enantiomer. Additionally, TAMOF-1 has been successfully incorporated into HPLC columns. These columns appear to be highly versatile. trans-2,3-Diphenyloxirane, a model compound typically used for calibration of chiral HPLC columns, has been resolved in a variety of polar and nonpolar solvents. To explore the advantages of this new stationary phase with respect to the widely used commercial columns, we resolved racemic mixtures of other small chiral molecules with different sizes and functional groups, demonstrating the promising wide applicability of our material.

\section{EXPERIMENTAL SECTION}

Materials. All reagents were of commercial grade and used without further purification: L-histidine ( $\geq 98 \%$, Iris Biotech $\mathrm{GmbH})$, ibuprofen ( $\geq 98 \%$, Sigma-Aldrich), thalidomide (98\%, Fluorochem), trans-2,3diphenyloxirane (98\%, Sigma-Aldrich), furoin ( $\geq 98 \%$, Sigma-Aldrich), benzoin (98\%, Sigma-Aldrich), 1-phenylethan-1-ol (98\%, SigmaAldrich), flavanone $\left(\geq 98 \%\right.$, Alfa Aesar), thionyl chloride $\left(\mathrm{SOCl}_{2}\right.$, $\geq 99 \%$, Sigma-Aldrich), hydrazine monohydrate $\left(\mathrm{NH}_{2} \mathrm{NH}_{2} \cdot \mathrm{H}_{2} \mathrm{O}\right.$, reagent grade, $98 \%$, Sigma-Aldrich), and sodium carbonate anhydrous $\left(\mathrm{Na}_{2} \mathrm{CO}_{3}\right.$, ACS reagent, $\geq 99.5 \%$, Sigma-Aldrich).

All solvents were of commercial grade and used without further purification: HPLC-grade methanol, ethanol, isopropanol, hexanes, acetonitrile, and tert-butyl methyl ether (VWR, Chem-Lab, and SigmaAldrich), $N, N$-dimethylformamide (peptide grade, $\geq 99.9 \%$, Iris Biotech GMBH), and diethyl ether ( $\geq 99 \%$, VWR).

A stainless-steel empty column $(100 \mathrm{~mm} \times 4.6 \mathrm{~mm}$ i.d. $)$ was obtained from Restek (Bellefonte, PA). A stainless-steel empty column $(150 \mathrm{~mm} \times 4.0 \mathrm{~mm}$ i.d.) was obtained from Chiral Technologies Europe SAS (Illkirch, Strasbourg, France).

Synthesis of (E)- $N^{\prime}-((E)$-(Dimethylamino)methylene)- $N, N$-dimethylformohydrazonamide (2). This reagent was prepared following a published procedure. ${ }^{14}$
Part I: To a $250 \mathrm{~mL}$ three-neck round-bottom flask (RBF) was added $150 \mathrm{~mL}$ of DMF, which was cooled in an ice-bath. Afterward, $28.6 \mathrm{~mL}$ of $\mathrm{SOCl}_{2}(0.39 \mathrm{~mol})$ was slowly added under stirring with a syringe (dropwise). The reaction mixture was stirred for $24 \mathrm{~h}$. After this time, the RBF was introduced in an ice-bath, and once the mixture was cold, 5 $\mathrm{mL}$ of $\mathrm{NH}_{2} \mathrm{NH}_{2} \cdot \mathrm{H}_{2} \mathrm{O}(0.1 \mathrm{~mol})$ dissolved in $15 \mathrm{~mL}$ of DMF was added very slowly, under stirring, with a syringe (dropwise and carefully; CAUTION: very exothermic reaction!!). The reaction mixture was stirred at room temperature for $48 \mathrm{~h}$. The precipitate was then filtered and washed with DMF $(20 \times 3 \mathrm{~mL})$ and $\mathrm{Et}_{2} \mathrm{O}(10 \times 3 \mathrm{~mL})$ to yield 20.5 $\mathrm{g}(0.095 \mathrm{~mol}, 95 \%$ yield $)$ of $\left(\mathrm{CH}_{3}\right)_{2} \mathrm{~N}(\mathrm{CH})=\mathrm{N}-\mathrm{N}=(\mathrm{CH}) \mathrm{N}\left(\mathrm{CH}_{3}\right)_{2}$. $2 \mathrm{HCl}(\mathbf{1})$.

Part II: $20.5 \mathrm{~g}$ of $\mathbf{1}(0.095 \mathrm{~mol})$ was weighed and dissolved in $100 \mathrm{~mL}$ of $\mathrm{H}_{2} \mathrm{O}$. In a different beaker, $10.6 \mathrm{~g}$ of $\mathrm{Na}_{2} \mathrm{CO}_{3}(0.1 \mathrm{~mol})$ was dissolved in $100 \mathrm{~mL}$ of $\mathrm{H}_{2} \mathrm{O}$. Both water solutions were then mixed (the $\mathrm{Na}_{2} \mathrm{CO}_{3}$ on top of the azine solution), and the desired product $\left(\mathrm{CH}_{3}\right)_{2} \mathrm{~N}$ $(\mathrm{CH})=\mathrm{N}-\mathrm{N}=(\mathrm{CH}) \mathrm{N}\left(\mathrm{CH}_{3}\right)_{2}$ (2) was purified by continuous extraction in $750 \mathrm{~mL}$ of $\mathrm{Et}_{2} \mathrm{O}$, at $50{ }^{\circ} \mathrm{C}$ during 2 days. The organic layer was concentrated in vacuo, and $12.95 \mathrm{~g}$ of $\mathbf{2}(0.09 \mathrm{~mol}, 96 \%$ yield $)$ was obtained as an orange solid, which was used without any further purification.

Synthesis of (S)-3-(1H-Imidazol-5-yl)-2-(4H-1,2,4-triazol-4-yl)propanoic Acid (S-HTA). 2 (6.3 g, $0.044 \mathrm{~mol})$ and L-histidine (3.1 g, $0.02 \mathrm{~mol}$ ) were mixed together in $150 \mathrm{~mL}$ of EtOH. The mixture was refluxed with stirring for $48 \mathrm{~h}$. The final solution was filtered off from unreacted L-histidine, and the solvent was removed under reduced pressure to afford an orange gel that was washed with EtOH to yield a white precipitate of $S$-HTA, that was collected by filtration, washed with $\mathrm{EtOH}(15 \times 3 \mathrm{~mL}), \mathrm{Et}_{2} \mathrm{O}(15 \times 3 \mathrm{~mL})$, and dried in air. Yield: $3.5 \mathrm{~g}$ $(0.017 \mathrm{~mol}, 85 \%)$. Anal. Calcd for $\mathrm{C}_{8} \mathrm{H}_{9} \mathrm{~N}_{5} \mathrm{O}_{2}$ (\%): C, 46.38; $\mathrm{H}, 4.38$; $\mathrm{N}, 33.80$. Found: C, 46.36; $\mathrm{H}, 4.52 ; \mathrm{N}, 33.78$. MS-ESI $(\mathrm{m} / \mathrm{z}):[\mathrm{M}+\mathrm{H}]^{+}$ calcd for $\mathrm{C}_{8} \mathrm{H}_{10} \mathrm{~N}_{5} \mathrm{O}_{2}, 208.1$; found, 208.1. IR (ATR, cm ${ }^{-1}$ ): 1637, $1601,1535,1463,1440,1397,1359,1294,1261,1209,1080,1031$, $1009,971,921,872,838,796,731,710,681,647,630,483,424 .{ }^{1} \mathrm{H}$ NMR $\left(400 \mathrm{MHz}, \mathrm{D}_{2} \mathrm{O}\right):{ }^{15} \delta(\mathrm{ppm}) 8.54(\mathrm{~d}, J=1.4 \mathrm{~Hz}, 1 \mathrm{H}), 8.49(\mathrm{~s}$, $2 \mathrm{H}), 7.11(\mathrm{~s}, 1 \mathrm{H}), 5.23(\mathrm{dd}, J=9.4,5.4 \mathrm{~Hz}, 1 \mathrm{H}), 3.63(\mathrm{dd}, J=15.7,5.4$ $\mathrm{Hz}, 1 \mathrm{H}), 3.52$ (dd, $J=15.7,9.4 \mathrm{~Hz}, 1 \mathrm{H}) .{ }^{13} \mathrm{C}\left\{{ }^{1} \mathrm{H}\right\} \mathrm{NMR}(101 \mathrm{MHz}$, $\left.\mathrm{D}_{2} \mathrm{O}\right): \delta(\mathrm{ppm}) 173.00(\mathrm{C}), 143.64(\mathrm{CH}), 133.79(\mathrm{CH}), 128.63(\mathrm{C})$, $117.16(\mathrm{CH}), 60.14(\mathrm{CH}), 28.55\left(\mathrm{CH}_{2}\right) \cdot[\alpha]^{25}{ }_{\mathrm{D}}=+4.64^{\circ}(c=0.74$, $\left.\mathrm{H}_{2} \mathrm{O}\right)$.

Synthesis of $\left[\mathrm{CU}\left(\mathrm{H}_{2} \mathrm{O}\right)_{2}(\mathrm{~S}-T A)_{2}\right] \cdot 6 \mathrm{H}_{2} \mathrm{O}$ (TAMOF-1). $\mathrm{Cu}^{\mathrm{II}}\left(\mathrm{CH}_{3} \mathrm{COO}\right)_{2} \cdot \mathrm{H}_{2} \mathrm{O}(0.48 \mathrm{~g}, 2.4 \mathrm{mmol})$ was dissolved in $50 \mathrm{~mL}$ of $\mathrm{H}_{2} \mathrm{O}$, and the resulting solution was slowly added to a $100 \mathrm{~mL}$ aqueous solution of HTA $(1.0 \mathrm{~g}, 4.8 \mathrm{mmol})$. The solution was stirred for $30 \mathrm{~min}$, allowing for the appearance of a precipitate. This blue polycrystalline powder (TAMOF-1) was filtered with a Nylon membrane filter (pore size: $0.45 \mu \mathrm{m}$, Filter-Lab), washed with $\mathrm{H}_{2} \mathrm{O}(50 \times 3 \mathrm{~mL})$, and dried in air. Yield: $1.1 \mathrm{~g}(70 \%)$. Anal. Calcd for $\mathrm{C}_{16} \mathrm{H}_{32} \mathrm{CuN}_{10} \mathrm{O}_{12}$ (\%): C, 30.99; $\mathrm{H}, 5.2 ; \mathrm{N}, 22.59$. Found: C, 30.79; H, 4.83; N, 22.30. IR (ATR, $\mathrm{cm}^{-1}$ ): $3289,1615,1532,1495,1395,1355,1263,1242,1211,1180,1116$, $1087,1015,979,891,845,752,701,660,647,549,511,472$. Single crystals of TAMOF-1 were obtained by slow diffusion of the $\mathrm{Cu}^{\mathrm{II}}\left(\mathrm{CH}_{3} \mathrm{COO}\right)_{2} \cdot \mathrm{H}_{2} \mathrm{O}$ and $\mathrm{S}$-HTA solutions in an H-tube.

Instrumentation. Aliquots from ibuprofen gravity separations from glass TAMOF-1 columns were analyzed by ultraperformance convergence chromatography with an ACQUITY UPC2 system equipped with a diode array detector (Waters Co.), and a CHIRALPAK IC column $(4.6 \times 100 \mathrm{~mm}, 3 \mu \mathrm{m})$ with an isocratic $\mathrm{CO}_{2} / \mathrm{ACN} / \mathrm{TFA}$ 88:12:0.5 mobile phase, at a $3 \mathrm{~mL} \mathrm{~min}^{-1}$ flow rate $(1500 \mathrm{psi})$, for a volume injection of $2 \mu \mathrm{L}$. Aliquots from thalidomide gravity separations were analyzed by HPLC chromatography with an Agilent 1200 Series system equipped with a diode array detector, and a CHIRALPAK IA column $(4.6 \times 250 \mathrm{~mm}, 5 \mu \mathrm{m})$ with a $\mathrm{MeOH} / \mathrm{ACN} 80: 20$ mobile phase with $0.1 \mathrm{mM}$ ammonium acetate, at $1 \mathrm{~mL} \mathrm{~min}^{-1}$ flow rate, for a volume injection of $5 \mu \mathrm{L}$. Comparative HPLC separations with column A were performed on a chromatographic system consisting of a Varian 9002 HPLC pump and a Varian $9050 \mathrm{UV} /$ vis detector (Palo Alto, CA). HPLC separations with column B were performed with an Agilent 1200 Series system equipped with a diode array detector. 
Table 1. Crystallographic Data and Refinement Parameters for the Crystal Structure of TAMOF-1 Collected at $100 \mathrm{~K}, 298 \mathrm{~K}$, in Desolvated State at $403 \mathrm{~K}$, and Again at $100 \mathrm{~K}$ after Rehydration, by Submerging the Single Crystal in a Drop of Distilled Water at Room Temperature

\begin{tabular}{|c|c|c|c|c|}
\hline & $100(2) \mathrm{K}$ & $298(2) \mathrm{K}$ & $403(2) \mathrm{K}$ & 100(2) K (rehydrated) \\
\hline empirical formula & $\mathrm{C}_{16} \mathrm{H}_{31.33} \mathrm{CuN}_{10} \mathrm{O}_{11.67}$ & $\mathrm{C}_{16} \mathrm{H}_{25.67} \mathrm{CuN}_{10} \mathrm{O}_{8.83}$ & $\mathrm{C}_{16} \mathrm{H}_{16} \mathrm{CuN}_{10} \mathrm{O}_{4}$ & $\mathrm{C}_{16} \mathrm{H}_{31} \mathrm{CuN}_{10} \mathrm{O}_{11.5}$ \\
\hline formula weight & 614.05 & 563.00 & 475.93 & 611.04 \\
\hline temp $/ \mathrm{K}$ & $100(2)$ & $298(2)$ & $404(2)$ & $100(2)$ \\
\hline wavelength/Å & 0.71073 & 0.71073 & 0.71073 & 0.71073 \\
\hline crystal system & cubic & cubic & cubic & cubic \\
\hline space group & $\mathrm{P}_{3} 32$ & $\mathrm{P}_{3} 32$ & $P 4_{3} 32$ & $\mathrm{P}_{3} 32$ \\
\hline$a / \AA$ & $20.120(4)$ & $20.172(2)$ & $20.262(2)$ & $20.1133(7)$ \\
\hline$b / \AA$ & $20.120(4)$ & $20.172(2)$ & $20.262(2)$ & $20.1133(7)$ \\
\hline$c / \AA$ & $20.120(4)$ & $20.172(2)$ & $20.262(2)$ & $20.1133(7)$ \\
\hline$\alpha / \operatorname{deg}$ & 90 & 90 & 90 & 90 \\
\hline$\beta / \operatorname{deg}$ & 90 & 90 & 90 & 90 \\
\hline$\gamma / \mathrm{deg}$ & 90 & 90 & 90 & 90 \\
\hline volume $/ \AA^{3}$ & $8145(4)$ & $8208(2)$ & $8319(3)$ & $8136.7(8)$ \\
\hline$Z$ & 12 & 12 & 12 & 12 \\
\hline$\rho_{\text {calc }} / \mathrm{g} \mathrm{cm}^{-3}$ & 1.502 & 1.367 & 1.140 & 1.496 \\
\hline$\mu / \mathrm{mm}^{-1}$ & 0.878 & 0.857 & 0.822 & 0.878 \\
\hline$F(000)$ & 3836 & 3496 & 2916 & 3816 \\
\hline crystal size $/ \mathrm{mm}^{3}$ & $0.05 \times 0.05 \times 0.03$ & $0.05 \times 0.05 \times 0.03$ & $0.05 \times 0.05 \times 0.03$ & $0.05 \times 0.05 \times 0.03$ \\
\hline $\begin{array}{l}\Theta \text { range for data } \\
\text { collection } / \text { deg }\end{array}$ & $1.753-35.178$ & $1.749-32.062$ & $1.741-27.108$ & $1.754-33.716$ \\
\hline index ranges & $\begin{array}{l}-12 \leq h \leq 27,-6 \leq k \leq 32 \\
-27 \leq l \leq 8\end{array}$ & $\begin{array}{l}-11 \leq h \leq 26,-7 \leq k \leq 26 \\
-6 \leq l \leq 30\end{array}$ & $\begin{array}{l}-6 \leq h \leq 21,-14 \leq k \leq 20 \\
-5 \leq l \leq 25\end{array}$ & $\begin{array}{l}-31 \leq h \leq 7,-21 \leq k \leq 26 \\
\quad-31 \leq l \leq 17\end{array}$ \\
\hline reflections collected & 18098 & 14121 & 11230 & 53327 \\
\hline ind reflections & 5693 & 4677 & 3063 & 5445 \\
\hline$R_{\mathrm{int}}$ & 0.0310 & 0.0578 & 0.0358 & 0.0400 \\
\hline completeness/\% & 98.9 & 97.5 & 99.3 & 99.9 \\
\hline absorption correction & none & multiscan & multiscan & multiscan \\
\hline $\begin{array}{l}\text { data/restraints/ } \\
\text { parameters }\end{array}$ & $5693 / 78 / 263$ & $4677 / 51 / 222$ & $3063 / 0 / 141$ & $5445 / 78 / 263$ \\
\hline GOF on $F^{2}$ & 1.043 & 0.986 & 1.071 & 1.085 \\
\hline $\begin{array}{l}\text { final } R^{a} \text { indexes } \\
\quad[I \geq 2 \sigma(I)]\end{array}$ & $R_{1}=0.0341, w R_{2}=0.0884$ & $R_{1}=0.0439, w R_{2}=0.1012$ & $R_{1}=0.0331, w R_{2}=0.0807$ & $R_{1}=0.0290, w R_{2}=0.0796$ \\
\hline $\begin{array}{l}\text { final } R^{a} \text { indexes } \\
\quad \text { [all data }]\end{array}$ & $R_{1}=0.0406, w R_{2}=0.0914$ & $R_{1}=0.0625, w R_{2}=0.1083$ & $R_{1}=0.0442, w R_{2}=0.0850$ & $R_{1}=0.0333, w R_{2}=0.0819$ \\
\hline Flack parameter & $-0.014(4)$ & $0.004(9)$ & $-0.016(9)$ & $-0.008(3)$ \\
\hline $\begin{array}{l}\text { largest diff. peak/hole/ } \\
\mathrm{e} \AA^{-3}\end{array}$ & $0.458 /-0.353$ & $0.431 /-0.278$ & $0.182 /-162$ & $0.509 /-0.271$ \\
\hline
\end{tabular}

Preparation of Glass TAMOF-1 Column. Glass columns $(60 \mathrm{~cm}$ total length, $1 \mathrm{~cm}$ outer diameter, $0.6 \pm 0.1 \mathrm{~cm}$ inner diameter) were used to prepare TAMOF-1 separation columns. TAMOF-1 was activated in a round flask at $2 \times 10^{-1}$ mbar and $403 \mathrm{~K}$ for $14 \mathrm{~h}$. The resulting TAMOF-1 powder was packed into the glass column over a 5 mm-thick compact cotton stopper by adding successive loads of $\sim 400$ $\mathrm{mg}$, and pressurized under $\mathrm{N}_{2}$ (99.999\% purity) at $\leq 4$ bar for $10 \mathrm{~min}$. After loading was completed, the column was filled with $100 \%$ acetonitrile and pressurized under $\mathrm{N}_{2}$ again until eluent level in the column reached over the top of the TAMOF-1 bed. The bed was then covered with a $5 \mathrm{~mm}$ thick sand layer. On average, $3 \mathrm{~g}$ loading of TAMOF-1 corresponds to $\sim 25 \pm 1 \mathrm{~cm}$ bed length. Before the $( \pm)$-ibuprofen and $( \pm)$-thalidomide separation tests, the columns were conditioned overnight under an acetonitrile flow (in the $0.05-0.10 \mathrm{~mL}$ $\mathrm{min}^{-1}$ range, leading to column head pressure in the $10-75 \mathrm{kPa}$ range). Eluent was pumped during columns conditioning and drug separation tests by using a Metrohm 877 Titrino plus apparatus.

Preparation of Packed Columns for Chiral HPLC. To pack the column A (100 mm $\times 4.6 \mathrm{~mm}$ i.d.) with TAMOF-1, $737 \mathrm{mg}$ (activated following previous procedure) was initially added via dry packing, and the column was pressurized using $100 \%$ acetonitrile at a high flow rate

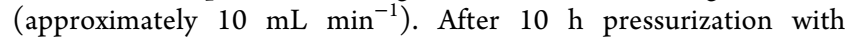
acetonitrile, the column was opened and an additional amount of
TAMOF-1 had to be added (due to packing of the material) and the eluent changed to $100 \%$ isopropanol (higher viscosity). This process of adding TAMOF-1 and packing was repeated until a total of $1550 \mathrm{mg}$ was added to the column (fully packed). After the column was fully packed, it was pressurized with $100 \%$ isopropanol at a high flow rate $(2$ $\mathrm{mL} \mathrm{min}^{-1}$, approximately $5000 \mathrm{psi}$ ) for $12 \mathrm{~h}$ to further ensure TAMOF1 was indeed fully packed and the column did not require any additional MOF. Before any data collection, the column was conditioned with the appropriate solvent system at a flow rate of $0.15 \mathrm{~mL} \mathrm{~min}^{-1}$ for $3 \mathrm{~h}$ before chromatographic experiments (approximately 15 column volumes). The above-prepared HPLC column was designated as column A.

Another column was prepared (hereinafter referred to as column B). To pack this second column with TAMOF-1, the $150 \mathrm{~mm} \times 4.0 \mathrm{~mm}$ i.d. column was coupled to a $150 \mathrm{~mm} \times 10 \mathrm{~mm}$ i.d. reservoir. This system was loaded with a slurry of TAMOF-1 in isopropanol/heptane 80:20 and pressurized with isopropanol/heptane 90:10 to a pressure of $\sim 150$ bar for $20 \mathrm{~min}$. The reservoir device was removed, and the column, containing ca. $1.8 \mathrm{~g}$ of TAMOF-1, was closed. Before any HPLC analyses, the column was conditioned by passing through it the mobile phase to be used (approximately the eluent volume equivalent to 15 column volumes).

Calculation of the Chromatographic Parameters. The selected parameters to assess separation efficiency were the retention factor $(k)$, 
separation factor $(\alpha)$, and resolution $\left(R_{\mathrm{S}}\right)$. These parameters were calculated using the following equations:

$$
\begin{aligned}
& k=\frac{t_{\mathrm{R} 1}-t_{\mathrm{M}}}{t_{\mathrm{M}}} \\
& \alpha=\frac{t_{\mathrm{R} 2}-t_{\mathrm{M}}}{t_{\mathrm{R} 1}-t_{\mathrm{M}}} \\
& R_{\mathrm{S}}=\frac{2\left(t_{\mathrm{R} 2}-t_{\mathrm{R} 1}\right)}{w_{1}+w_{2}}
\end{aligned}
$$

where $t_{\mathrm{M}}$ is the column void time, $t_{\mathrm{R} 1}$ and $t_{\mathrm{R} 2}$ are the retention times, and $w_{1}$ and $w_{2}$ are the peak widths of each peak.

Computational Details. Classical simulations were carried out using RASPA molecular simulation software. ${ }^{16}$ An all-atom flexible model is used to model each enantiomer, except the heterocycle part (e.g., aromatic ring in the ibuprofen molecule), which is considered rigid. The intramolecular potential for the guest species comprises two-body (bond), three-body (angle), four-body (dihedral) interactions, and the electrostatic Coulomb term. Parameters are given in the original reference OPLS-AA. TAMOF-1 was considered as rigid structure, and Lennard-Jones parameters are taken from the DREIDING ${ }^{17}$ force field, except those for metallic atoms that were taken from UFF force field. ${ }^{18}$ The charges of the host atoms are obtained via Qeq calculations using the RASPA code. Finally, Lennard-Jones (LJ) potentials are used to describe the intermolecular host-guest and guest-guest interactions using Lorentz-Berthelot mixing rules. This methodology has been validated with many previous works. ${ }^{19}$

Adsorption enthalpy was calculated with the Widom Test Particle insertion method at infinite dilution. ${ }^{20}$ The Configurational Bias Monte Carlo (CBMC) method was used for the insertion MC move.

We have studied the transport and diffusion behavior using Molecular Dynamics (MD) simulations at several temperatures (300, $400,500,600$, and $800 \mathrm{~K}$ ) and fitting the self-diffusion values at infinite dilution conditions using the following Arrhenius function: $\log \left(D / D_{0}\right)$ $=\varepsilon / k_{\mathrm{B}} T$, where $\varepsilon$ is the activation energy, $D_{0}$ is a pre-exponential factor (the self-diffusion coefficient at infinite temperature), $k_{\mathrm{B}}$ is the Boltzmann constant, and $T$ is temperature. $\varepsilon$ and $D_{0}$ are fitted using a linear regression. Ten simulations for each temperature (using different random seeds) were used to estimate the average value of the selfdiffusion coefficient at this temperature.

Molecular Dynamics (MD) simulations were performed in the canonical ensemble (NVT), with a cutoff of $12 \AA, 0.5$ fs of time step, $500 \mathrm{ps}$ of equilibration time, $5 \mathrm{~ns}$ of production time, and a $2 \times 2 \times 2$ supercell. Ewald summation was used to avoid energy divergences in the electrostatic calculation. We have used the Nose-Hoover thermostat. The algorithms are modified for rigid (or semirigid) molecules in the RASPA code.

Crystallography. X-ray single-crystal diffraction data of TAMOF-1 were collected at 100(2) K (as prepared), $298 \mathrm{~K}, 403 \mathrm{~K}$, and again at $100(2) \mathrm{K}$ (rehydrated), on a Bruker APEX duo diffractometer with an APEX II CCD detector using Mo $_{\alpha}(\lambda=0.71073 \AA)$ and equipped with an Oxford Cryostrem 700 plus. Crystal structure solution was obtained using SIR2011, and refinement was performed using SHELXL $^{21}$ v. $2018 / 3$ under the ShelXle (Rev. 912) interface. ${ }^{22}$ All non-hydrogen atoms were refined anisotropically. Crystallographic data and refinement parameters are summarized in Table 1.

Crystallographic data have been deposited at the Cambridge Crystallographic Database Centre, with deposition numbers 1898811 (as-prepared, $100 \mathrm{~K}), 1898970$ (298 K), 1898969 (404 K), and 1898971 ( $100 \mathrm{~K}$, rehydrated). Copy of data can be obtained free of charge on application to the CCDC, Cambridge, UK via www.ccdc. cam.ac.uk/data request/cif.

\section{RESULTS AND DISCUSSION}

Synthesis and Crystal Structure. TAMOF-1, with formula $\left[\mathrm{Cu}(S-\mathrm{TA})_{2}\right] \cdot n \mathrm{H}_{2} \mathrm{O}$, can be readily crystallized at room temperature from a water solution of its components after a few hours of being mixed. Precipitation can also be induced by layering the solution with an organic solvent. Phase purity of single crystals and polycrystalline samples prepared by either method was confirmed using Le Bail refinement of powder X-ray diffraction (PXRD) (Figure S1). Single-crystal X-ray diffraction (XRD) data analysis confirmed that TAMOF-1 is a threedimensional network built from the interlinking of $\left\{\mathrm{Cu}(S-\mathrm{TA})_{2}\right\}$ units (Figure 1a). Each pseudo-octahedral $\mathrm{Cu}^{\mathrm{II}}$ center is coordinated in the equatorial positions to imidazolate and triazolate connectors from four different deprotonated S-TA linkers. The axial positions are occupied by two terminal water molecules, with elongated coordination bonds $(\mathrm{Cu}-\mathrm{O}>2.45 \AA$ at $100 \mathrm{~K}, \mathrm{Cu}-\mathrm{O}>2.49 \AA$ at $300 \mathrm{~K}$ ) due to the Jahn-Teller effect. Overall, each metal center is connected to four neighboring sites by four S-TA linkers, which orientate imidazolate and triazolate groups above and below the plane, respectively, and leave the C-term carboxylate groups uncoordinated, to conform a neutral framework with $\mathrm{P}_{3} 32$ cubic symmetry. Homochirality was also confirmed by the Flack parameter value of $-0.014(4)$ (Table 1). For a clearer structural description, we simplified the connectivity of the framework into its underlying net. We considered $\left\{\mathrm{Cu}(S-\mathrm{TA})_{2}\right\}$ units as secondary building units (SBUs) acting as 3-c nodes and S-TA ligands as linkers. As shown in Figure 1b, TAMOF-1 displays a $(10,3)$-a connected srs-type net. This topology has been previously reported for other frameworks based on azolate connectors. ${ }^{23}$ This connectivity generates an open framework with 3D intersected channels that are filled with water molecules in the as-made material. As shown in Figure 1c, complete removal of the guest leaves a porous structure with a solventaccessible volume close to $41 \%$ of the total $\left(3307.7 \AA^{3}\right.$ at $403 \mathrm{~K}$; see Table S1) and pore diameters above 0.8 and $0.5 \mathrm{~nm}$ for the largest included $\left(D_{\mathrm{i}}\right)$ and free $\left(D_{\mathrm{f}}\right)$ spheres, respectively.

Permanent Porosity. TAMOF-1 is stable upon dehydration. A sequence of three single-crystal XRD data collections, for the same crystal, were carried out at $298 \mathrm{~K}, 403 \mathrm{~K}$, and again at $100 \mathrm{~K}$ after rehydration (Figure 1d). In all four experiments, the unit cell parameters remained practically unaltered (Table 1). However, the crystal structure at $403 \mathrm{~K}$ revealed that all water molecules were removed, including the coordinating ones. At this temperature, negligible residual electron density $(<0.2 \mathrm{e}$ $\AA^{-3}$ ) was found in the channels, indicating they are essentially empty. The $\mathrm{Cu}$ centers adopt a square planar coordination geometry (Table S2). Beyond the solvent loss, no structural modifications were observed, leaving a highly porous structure available. The dehydration process is reversible. To test this, the same single crystal was immersed in a drop of distilled water and remounted in the diffractometer. The structure of the rehydrated structure was found to be indistinguishable from the original one. Therefore, TAMOF-1 is insensitive to hydration/dehydration cycling, confirming the structural robustness of this chiral MOF. This is consistent with our variable-temperature PXRD study, which shows how the structure of the framework remains unchanged up to $200{ }^{\circ} \mathrm{C}$. Chemical stability was also evaluated by incubating a polycrystalline sample in distilled water for 4 days in neutral, acid, and basic media (Figure S2). PXRD Le Bail refinement of the solids and inductively couple plasma (ICP) analysis of the supernatant both confirm the structural integrity and negligible metal leaching, ruling out chemical degradation (Figure S3 and Tables S3 and S4).

Previous reports confirm the ability of basic azolates to provide frameworks with outstanding chemical stability due to 
strong metal-nitrogen bonds. ${ }^{24}$ Permanent porosity was investigated by means of $\mathrm{N}_{2}$ adsorption-desorption isotherms at $77 \mathrm{~K}$ after activation of the solid at $10^{-3} \mathrm{mbar}$ and $423 \mathrm{~K}$ for 12 h. TAMOF-1 was shown to display a type-I isotherm characteristic of microporous materials with a multipoint BET over $980 \pm 50 \mathrm{~m}^{2} \mathrm{~g}^{-1}$ (averaged from six repetitions) and a micropore volume of $0.38 \pm 0.02 \mathrm{~cm}^{3} \mathrm{~g}^{-1}$ with a narrow pore size distribution (PSD) centered at $0.7 \mathrm{~nm}$ (Figure S4 and Table S5). Experimental surface area and PSD values are consistent with the computed data from geometrical analysis of the crystal structure of TAMOF-1, confirming the analytical purity of the solid. As compared to other chiral MOFs, the incorporation of triazolate metal connectors $\left(\mathrm{p} K_{\mathrm{a}}=9.3\right)^{25}$ to the $\mathrm{N}$-term position in histidine yields a chiral, robust framework that can retain its porosity after activation and does not suffer from the chemical limitations imposed by the weak metal binding sites inherent to amino acids or oligopeptides. Even more, the 3D network of helicoidal channels in TAMOF-1 deploys a manifold of sites, $\mathrm{Cu}$ (II) vacancies, and polar groups such as free carboxylic acid sites, triazole, and imidazole units, ideal to modulate the interaction of the framework with chiral guests for recognition and discrimination of enantiomers.

Enantioselective Chromatographic Separations. This encouraged us to test the performance of TAMOF-1 as a chiral stationary phase in chromatographic preparative separation experiments. For this purpose, a glass column was packed with a polycrystalline batch of the TAMOF-1 (see Experimental Section for details), and a solution of racemic $( \pm)$-ibuprofen was run through, using acetonitrile as the eluent. Ibuprofen is a widely employed nonsteroidal anti-inflammatory drug, typically prescribed as the racemate, even though the $(S)$-ibuprofen enantiomer exhibits a much stronger inhibitory activity than (R)-ibuprofen. ${ }^{26}$ We chose this first analyte because of its appropriate molecular dimensions $\left(6.4 \times 6.7 \times 12.5 \AA^{3}\right)$, fitting well to the contour of the channels (Figure S5a), and its relevance in previous enantioselective separations with other MOFs. ${ }^{27}$ At near-atmospheric pressure, the two enantiomers descend through the column as two different fronts. Enantiopure $(S)$-ibuprofen exits the column first, due to the preferred interaction of $(R)$-ibuprofen with TAMOF-1, resulting in a slower elution of the $(R)$-enantiomer. The two fronts are fully resolved in these conditions (Figure 2a), with quantitative yields for the enantiopure products; $99 \%$ of $(S)$ - and $92 \%(R)$-ibuprofen at ee $>99 \%$ were recovered starting with 6.9 $\mathrm{mg}$ of $( \pm)$-ibuprofen with a flow rate of $0.09 \mathrm{~mL} \mathrm{~min}^{-1}$. This process is remarkable because no high pressure, or temperature, or a mixture of solvents were needed for separating the enantiomers. Furthermore, the analyte is completely removed by the solvent, leaving the column ready for reuse without additional treatment.

In analogous conditions, we were also able to quantitatively separate $( \pm)$-thalidomide $\left(6.9 \times 7.7 \times 13.6 \AA^{3}\right.$, Figure S5b), a turning point for regulatory agencies to enforce stereochemical characterization of drugs during the 20th century, due to the late discovery of the teratogenic properties of the $(S)$-enantiomer of thalidomide. $^{28}$ We chose thalidomide because it is quite different from ibuprofen in chemical functionalities, while possessing similar molecular volumes. The fact that both can be separated using the same solvent and conditions confirms the versatility of this metal-organic CSP for the separation of chiral drugs. ( \pm )-Thalidomide is also resolved (Figure $2 \mathrm{~b}$ ) with quantitative yields of $78 \%$ for $(S)$ - and $96 \%$ for $(R)$-thalidomide at ee $>99 \%$, starting with $2 \mathrm{mg}$ of $( \pm)$-thalidomide (flow rate
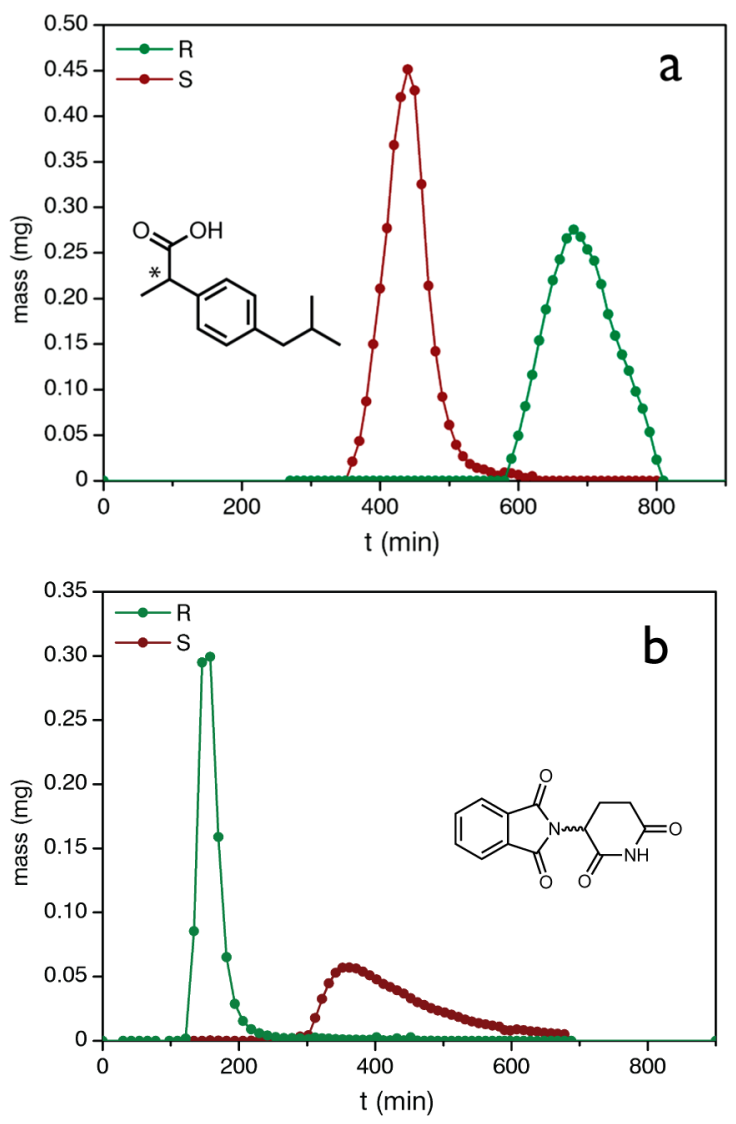

Figure 2. Gravity chromatographic separations at room temperature with a glass TAMOF-1 column with $100 \%$ acetonitrile as the mobile phase: (a) ( \pm )-ibuprofen; (b) ( \pm )-thalidomide.

$\left.0.06 \mathrm{~mL} \mathrm{~min}^{-1}\right)$. Remarkably, in the case of thalidomide, $(R)$ thalidomide elutes first contrary to what is observed for ibuprofen.

Theoretical Calculations. To better understand the mechanism of chiral separation, we carried out Monte Carlo simulations for the adsorption of ibuprofen and thalidomide using well-validated methods and models (see computational details in the Experimental Section for more information). ${ }^{29} \mathrm{We}$ first analyzed the thermodynamic contribution to the separation of both drugs by calculating the enthalpy of adsorption $\left(\Delta H_{\mathrm{st}}\right)$ for each enantiomer with the Widom Test Particle insertion method at infinite dilution. ${ }^{30} \Delta H_{\text {st }}$ was obtained from the enthalpy differences between the molecules in the gas phase and inside the structure of the desolvated TAMOF-1. These values are independent of the state or aggregation or the solvent and are meaningful to compare relative differences for TAMOF-1 enantiomer interactions. For ibuprofen, the calculated difference in enthalpies of adsorption $\left(\Delta H_{\mathrm{st}}^{\mathrm{RS}}\right)$ is $-27.34 \mathrm{~kJ} / \mathrm{mol}$, which is indicative of the preference of TAMOF-1 to interact with $(R)$ ibuprofen. In turn, for the case of thalidomide, the difference in enthalpies of adsorption is of $1.66 \mathrm{~kJ} / \mathrm{mol}$ and suggests a higher preference for $(S)$-thalidomide. In the absence of direct crystallographic evidence, ${ }^{31}$ we next analyzed the binding-site of the drug enantiomers in TAMOF-1 after energy minimization (Figure $3 a, b$ ) to understand the origin of these differences. The adsorption of ibuprofen is controlled by coordination to the vacant site of $\mathrm{Cu}(\mathrm{II})$ and the formation of a $\mathrm{H}$-bond with the triazole group. According to our simulations, these bonds elongate from 2.35 and $1.63 \AA$ for $(R)$ - to 2.72 and $1.75 \AA$ for a 

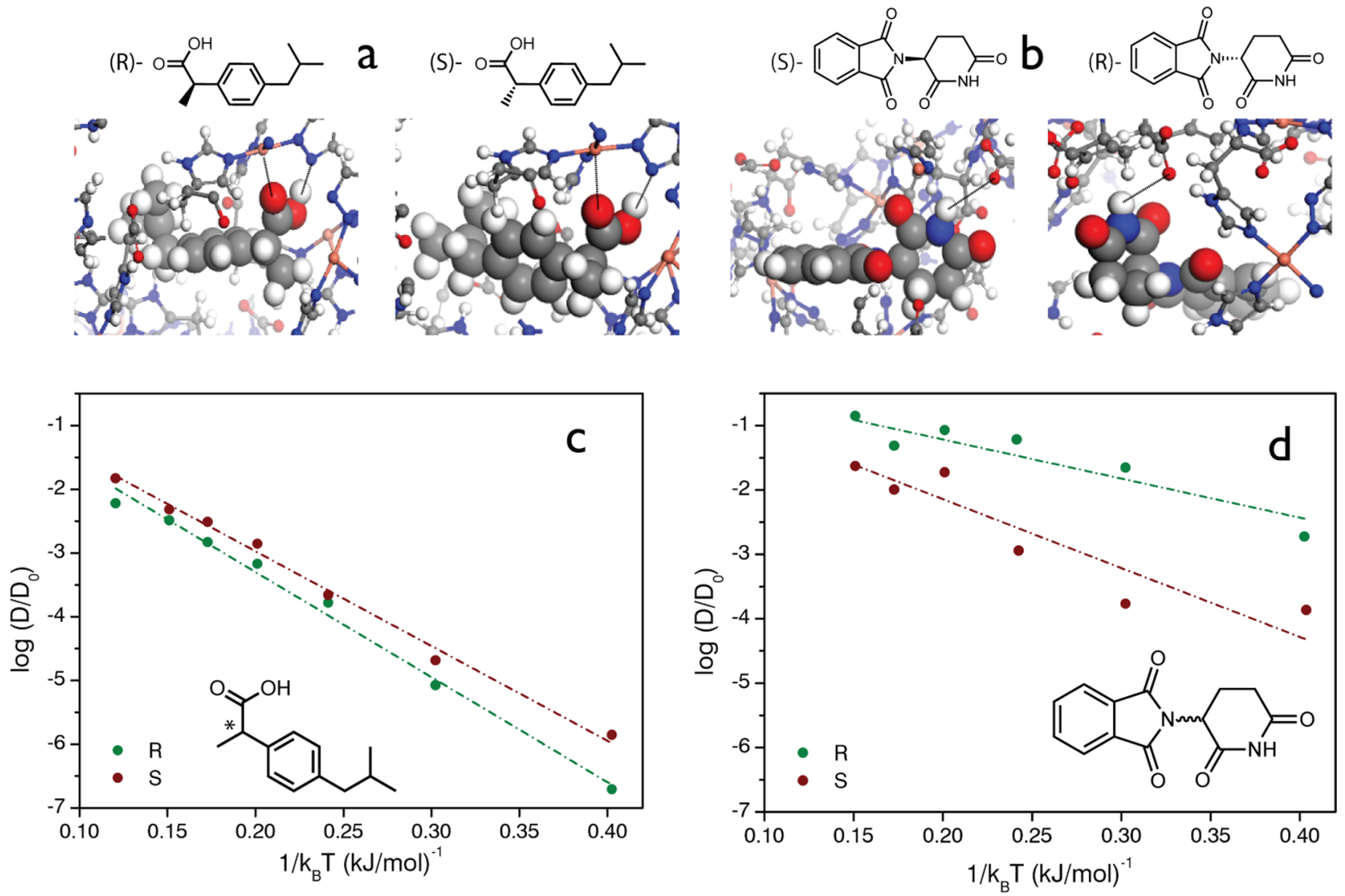

Figure 3. Binding geometries of ibuprofen (a) and thalidomide (b) enantiomers upon adsorption in TAMOF-1 calculated with Monte Carlo simulations. The most relevant interactions in directing guest binding are annotated with a dotted line. Arrhenius plot for the diffusion of ibuprofen (c) and thalidomide (d) enantiomers calculated with Molecular Dynamics.

weaker interaction with $(S)$-ibuprofen, due to small changes in the configuration of the adsorbed enantiomers. In turn, the smaller $\Delta H_{\mathrm{st}} \mathrm{RS}$ calculated for thalidomide originates from the presence of a $\mathrm{H}$-bond between the phthalimide ring and the free carboxylic groups in $S$-TA that elongates from 2.82 for $(S)$ - to $2.95 \AA$ for $(R)$-thalidomide combined with weak changes to the van der Waals interactions from a better fit of the first to the shape of the channels. Overall our simulations suggest that TAMOF-1 might behave as a versatile CSP due to the combination of chiral channels and weak binding sites for lowenergy separation of enantiomers. The combination of weak host-guest interactions with sufficiently high $\Delta H_{\text {st }}$ differences in TAMOF-1 may avoid strong pinning of one of the enantiomers to the pore walls, whereas it enables quantitative separation. We confirmed experimentally that none of the enantiomers were permanently trapped because both enantiomers were quantitatively recovered by continuous elution of acetonitrile. Large adsorption energies can lead to long retention times and broad chromatographic peaks; therefore, an optimal CSP is expected to display an optimal balance between $\Delta H_{\text {st }}{ }^{R S}$ and enantiomer diffusivity. This last point was studied with Molecular Dynamics (MD) by calculating the activation energies for the diffusion of both drugs with the corresponding Arrhenius plots (Figure 3c,d). From the Arrhenius equation, we can estimate that the self-diffusion coefficient $(D)$ of $(S)$ ibuprofen is 1 order of magnitude faster than the $(R)$ enantiomer at infinite dilution conditions (ca. $1.0 \times 10^{-11}$ and $5.7 \times 10^{-12} \mathrm{~m}^{2} / \mathrm{s}$, respectively). $(R)$-Thalidomide also diffuses slightly faster, $8 \times 10^{-12} \mathrm{~m}^{2} / \mathrm{s}$, than the $(S)$-enantiomer $(2 \times$ $\left.10^{-12} \mathrm{~m}^{2} / \mathrm{s}\right)$. The relative differences between the activation energies of the $(R)$ - and $(S)$-enantiomers for both drugs are comparable to the corresponding differences of binding energies.

Structural flexibility was also studied by performing energy minimizations of the structure with an empty structure and with one loaded molecule of ibuprofen and thalidomide. Additionally, we performed $\mathrm{MD}$ simulations at $300 \mathrm{~K}$ in the canonical ensemble. We have used the UFF4MOF force field for the atoms of the structure. ${ }^{32}$ No significant structural behaviors have been found that point beyond the thermal motion of the atoms. Neither have observed significant rotations of ligands that qualitatively could make a difference with respect to predictions of rigid models. So, the study of the transport of molecules using flexible models was not considered suitable or profitable.

Enantioselective HPLC Chromatography. After the finding of these promising results, we engineered an HPLC column to further explore the possibilities that TAMOF-1 has to offer as a CSP. An empty stainless-steel column $(100 \mathrm{~mm} \times 4.6$ $\mathrm{mm}$ ) was packed with $1.55 \mathrm{~g}$ of TAMOF-1 (column A, see Experimental Section for details). Prior to data collection, the column was conditioned with the appropriate solvent system at a flow rate of $0.15 \mathrm{~mL} \mathrm{~min}^{-1}$ for $3 \mathrm{~h}$ (approximately 15 column volumes). As model analyte, we selected racemic trans-2,3diphenyloxirane (i.e., a mixture of $(2 S, 3 S)$-2,3-diphenyloxirane and $(2 R, 3 R)-2,3$-diphenyloxirane), an analyte typically used to calibrate HPLC columns. The versatility of TAMOF-1 allowed for baseline resolution in a variety of solvent systems encompassing different solvating abilities and polarities, such as 95:5 hexanes/isopropanol, $100 \%$ isopropanol (IPA), and $100 \%$ acetonitrile (ACN) (Figure $4 \mathrm{a})$. The efficiency of the 


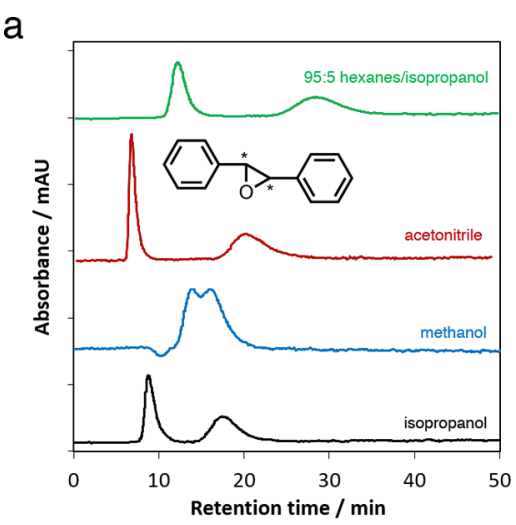

b

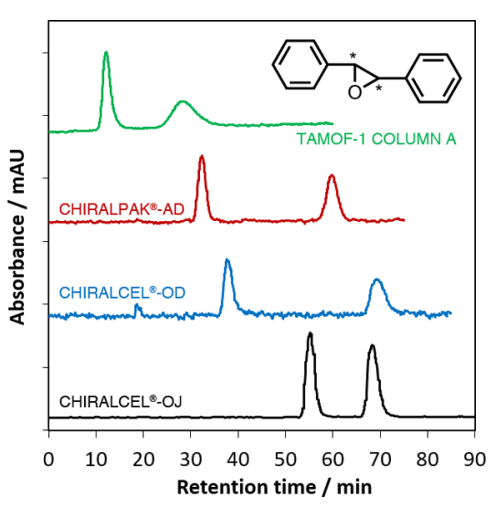

Figure 4. Representative chromatograms for the separation of trans2,3-diphenyloxirane enantiomers with HPLC column packed with TAMOF-1: (a) Separation with different mobile phases using column A (see Experimental Section for details): isopropanol, methanol, acetonitrile, and 95:5 hexanes/isopropanol (v/v). (b) Comparison with commercial columns CHIRALPAK-AD, CHIRALCEL-OD, and CHIRALCEL-OJ in 95:5 hexanes/isopropanol (v/v). For detailed HPLC conditions, see Tables 2 and 3 . In all cases, the $(S, S)$ enantiomer corresponds to the first peak.

chiral resolution of trans-2,3-diphenyloxirane in terms of separation factor $(\alpha)$, resolution $\left(R_{\mathrm{S}}\right)$, and retention times is shown in Table 2, emphasizing TAMOF-1's ability to separate enantiomers under analytic HPLC conditions employing diverse elution systems. Hence, this material can be considered as a bifunctional chiral stationary phase because it operates efficiently using either nonpolar (95:5 hexanes/IPA) or polar (100\% ACN, 100\% IPA) solvent conditions. The same column was also able to resolve furoin (i.e., 1,2-di(furan-2-yl)-2hydroxyethan-1-one) in a 50:50 ethanol $/ n$-hexane mixture (Table 2 and Figure S6). An additional demonstration of the versatility of TAMOF-1 is CSP regarding mobile phase and analyte.

For comparison, the chiral resolution capability of three widely used commercial columns was also determined with racemic trans-2,3-diphenyloxirane: CHIRALPAK-AD, CHIRALCEL-OJ, and CHIRALCEL-OD (Figure 4b). The optimal separation conditions, separation times of the eluted enantiomers, and resolutions are shown in Table 3. While each column is capable of resolving trans-2,3-diphenyloxirane, the limitation for these columns is the need to use highly hydrophobic solvent systems, 95:5 hexane/IPA in this case. Furthermore, the TAMOF-1 packed HPLC column yields competitive separation in the same working conditions. Taken together, the data suggest that the TAMOF-1 packed HPLC column yields highly efficient chiral resolutions and may exceed
Table 2. Chromatographic Parameters of the Separation of trans-2,3-Diphenyloxirane and Furoin in Different Solvent Systems with TAMOF-1 HPLC Column A $^{a}$

\begin{tabular}{|c|c|c|c|c|c|}
\hline Analyte & $\begin{array}{l}\text { Mobile } \\
\text { phase }\end{array}$ & $R_{S}$ & $\alpha$ & $\begin{array}{c}t_{\mathrm{R} 1} \\
(\min )\end{array}$ & $\begin{array}{c}t_{\mathrm{R} 2} \\
(\min )\end{array}$ \\
\hline \multirow{6}{*}{$\begin{array}{l}\text { trans-2,3- } \\
\text { diphenyl } \\
\text { oxirane }\end{array}$} & IPA & 1.73 & 2.92 & 8.71 & 17.38 \\
\hline & $\mathrm{MeOH}$ & $-{ }^{\mathrm{b}}$ & 1.21 & 13.74 & 15.82 \\
\hline & $\mathrm{ACN}$ & 2.55 & 6.38 & 6.70 & 20.12 \\
\hline & $95: 5$ & & & & \\
\hline & Hex/ & 1.37 & 3.06 & 12.12 & 28.47 \\
\hline & IPA & & & & \\
\hline \multirow{3}{*}{$\underset{\substack{\text { OH } \\
\text { furoin }}}{\mathrm{O}}$} & $50: 50$ & & & & \\
\hline & Hex/ & 1.12 & 1.57 & 67.29 & 103.36 \\
\hline & EtOH & & & & \\
\hline
\end{tabular}

${ }^{a}$ Flow rate $=0.15 \mathrm{~mL} \mathrm{~min}{ }^{-1}$, detection wavelength set to $254 \mathrm{~nm}$, total injection time adapted for each run to be ca. twice the retention time for the corresponding analyte. ${ }^{b}$ No baseline resolution achieved.

Table 3. Comparison of the Separation of trans-2,3Diphenyloxirane by the TAMOF-1 Column A versus CHIRALPAK AD, CHIRALCEL OJ, and CHIRALCEL OD Commercial Columns ${ }^{a}$

$\begin{array}{lllll} & \text { TAMOF-1 } & \mathrm{AD}^{b} & \mathrm{OD}^{c} & \mathrm{OJ}^{d} \\ \text { dimensions }(\mathrm{mm}) & 100 \times 4.6 & 250 \times 4.6 & & \\ (S, S) \text { time }(\mathrm{min}) & 12.1 & 32.3 & 37.6 & 55.3 \\ (R, R) \text { time }(\mathrm{min}) & 28.5 & 59.6 & 69.2 & 68.4 \\ \text { resolution }\left(R_{S}\right) & 1.37 & 4.98 & 5.75 & 2.63 \\ \% \text { area }(S, S) & 50.4 & 49.5 & 50.8 & 49.8 \\ \% \text { area }(R, R) & 49.6 & 50.5 & 49.2 & 50.2 \\ \text { total time }(\min ) & 40 & 75 & 80 & 80\end{array}$

${ }^{a}$ Mobile phase 95:5 hexanes/isopropanol (v/v), $0.15 \mathrm{~mL} \mathrm{~min}^{-1}$, detection wavelength set to $254 \mathrm{~nm}$, total injection time adapted for each run to be ca. twice the retention time for the corresponding analyte. ${ }^{b}$ CHIRALPAK AD. ${ }^{c}$ CHIRALCEL OJ. ${ }^{d}$ CHIRALCEL OD.

commercial column performance in terms of elution system versatility. The broader peaks obtained with TAMOF-1 could be related to its heterogeneous particle size. The columns were packed using the as-prepared material, with a random particle size between 0.2 and $10 \mu \mathrm{m}$, according to DLS data (Figure S7). Studies to confirm this hypothesis are underway.

To further explore the capabilities of TAMOF-1, we packed a second longer HPLC column $(150 \mathrm{~mm} \times 4.0 \mathrm{~mm})$ with $1.80 \mathrm{~g}$ of TAMOF-1 (column B, see methods for experimental details). A better separation was obtained for trans-2,3-diphenyloxirane, and using a variety of mobile phases (Table 3 and Figure S8). With the same column, we successfully achieved HPLC separations of a variety of other racemic mixtures, including 1phenylethan-1-ol, benzoin, or flavanone with different degrees of resolution (Table 4 and Figures S9-S12). These results ultimately demonstrate the potential versatility of TAMOF-1 to optimize chromatographic separation conditions for the direct HPLC separation of structurally diverse chiral small molecules. 
Table 4. Chromatographic Parameters of the Separation of Different Racemic Mixtures by a TAMOF-1 HPLC Column $\mathbf{B}^{a}$

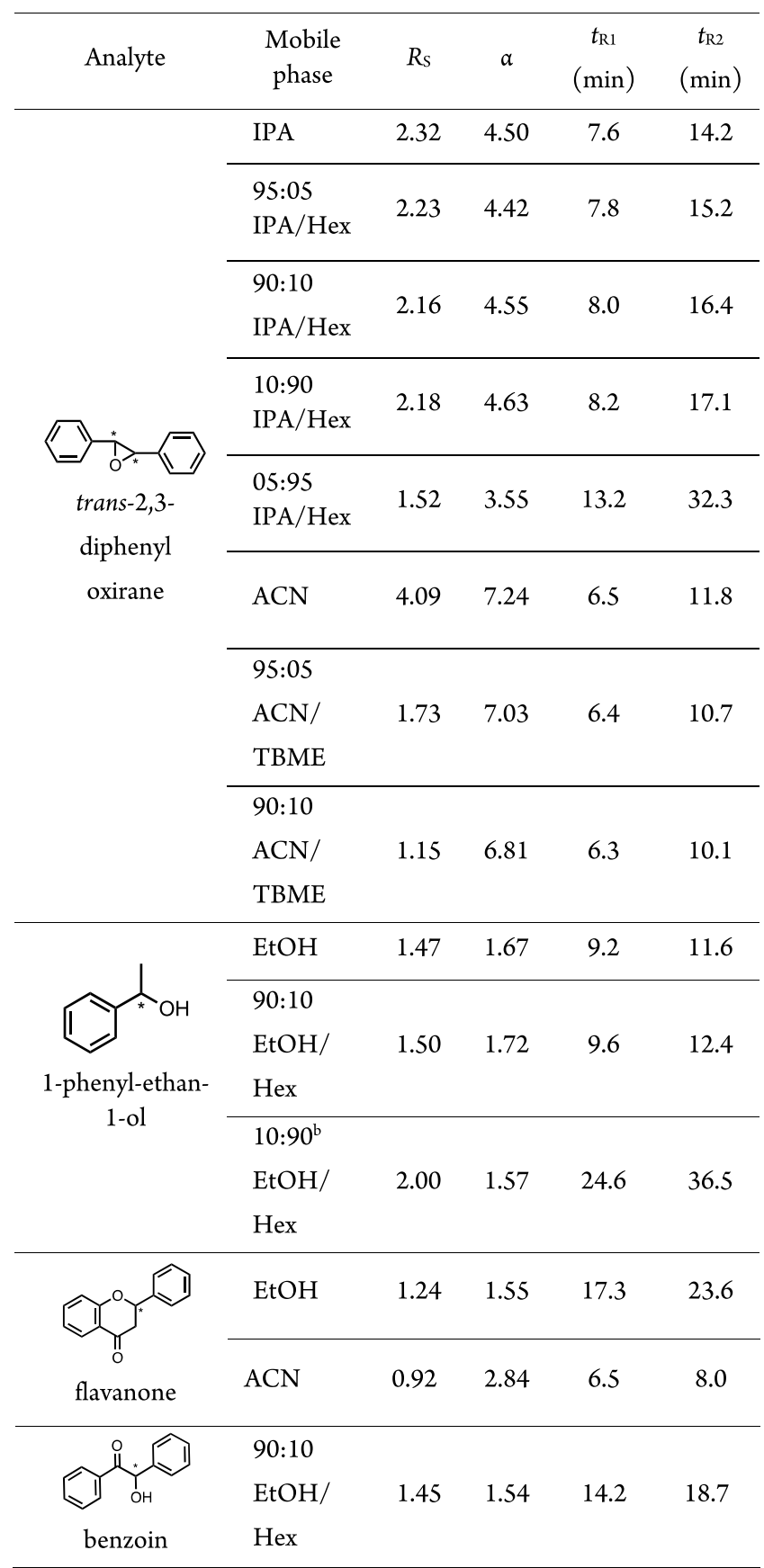

${ }^{a} 0.2 \mathrm{~mL} \mathrm{~min}{ }^{-1}$ flow rate unless otherwise stated, detection wavelength set to $254 \mathrm{~nm}$ for 1-phenyl-ethan-1-ol and benzoin, $230 \mathrm{~nm}$ for trans2,3-diphenyloxirane, and $220 \mathrm{~nm}$ for flavanone; total injection time adapted for each run to be ca. twice the retention time of the

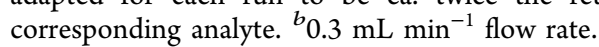

\section{CONCLUSIONS}

Functionalization of the natural amino acid L-histidine with a $4 \mathrm{H}$-1,2,4-triazole moiety, by transformation of its $-\mathrm{NH}_{2}$ group, yields an enantiopure ligand that self-assembles with $\mathrm{Cu}$ (II) cations in water to build a porous $3 \mathrm{D}$ homochiral metal organic framework, TAMOF-1. This novel MOF is highly porous and stable upon complete solvent loss, as well as in water and polar or nonpolar solvents. Thanks to its robust porous structure, with helicoidal $1 \mathrm{~nm}$-wide channels running in the three directions (cubic structure), TAMOF-1 works as a highly versatile chiral stationary phase (CSP) for the enantiomeric resolution of chiral organic molecules using either polar (acetonitrile, alcohols) or nonpolar (hexanes) solvent conditions, allowing for the alternative/successive use of either of them.

According to theoretical studies, this performance arises from the combination of chiral channels and weak binding sites allowing for low-energy separation of enantiomers without any strong binding/recognition sites. This feature, along with its chemical and mechanical stability, allows working under HPLC conditions. Comparative studies show that TAMOF-1 may outperform the chiral separation capability of some commercial chiral HPLC columns.

The improved resolution of racemic mixtures with TAMOF1, along with its compatibility with multiple solvent systems, makes it highly desirable as a chiral stationary phase for industrial size applications. It is worthy to highlight that TAMOF-1 can be prepared in the multikilogram scale due to its quantitative and straightforward synthesis as well as the accessibility of the starting reagents and solvents utilized in its preparation.

\section{ASSOCIATED CONTENT}

\section{Supporting Information}

The Supporting Information is available free of charge on the ACS Publications website at DOI: $10.1021 /$ jacs.9b06500.

Crystallographic data for TAMOF-1 at $100 \mathrm{~K}$ (CIF) Crystallographic data for TAMOF-1 at $298 \mathrm{~K}$ (CIF) Crystallographic data for TAMOF-1 at $403 \mathrm{~K}$ (CIF) Crystallographic data for rehydrated TAMOF-1 at $100 \mathrm{~K}$ (CIF)

Powder XRD data; adsorption isotherms; adsorption models; additional chromatographic separation data; dynamic light scattering; single-crystal crystallographic data and refinement parameters; porosity analysis; and ICP-MS (PDF)

\section{AUTHOR INFORMATION}

\section{Corresponding Authors}

*anton.vidal@icrea.cat

*s.calero@tue.nl

*melissa.reynolds@colostate.edu

*carlos.marti@uv.es

*jrgalan@iciq.es

ORCID

José Luis Núñez-Rico: 0000-0001-8629-4908 Salvador R.G. Balestra: 0000-0002-2163-2782 Neyvis Almora-Barrios: 0000-0001-5269-2705 Juanjo Cabezas-Giménez: 0000-0002-8424-7101 Anton Vidal-Ferran: 0000-0001-7926-1876

Melissa Reynolds: 0000-0002-1836-7324

Carlos Martí-Gastaldo: 0000-0003-3203-0047

José Ramón Galán-Mascarós: 0000-0001-7983-9762

Present Address

${ }^{O}$ School of Pharmacy, University of Nottingham, Nottingham NG7 2RD, United Kingdom

Notes

The authors declare the following competing financial interest(s): M.N.C.O., V.L. and J.R.G.M. are inventors in 
European patent applica-tion No.: EP16382480.8, filed by ICIQ and ICREA (Priority date: 21/10/2016) protecting the chemical structure of TAMOF-1 and its derivatives and analogues, along with their applications, including but not limited to their use in enanti-omeric separations. This patent has been licensed to Orchestra Scientific S.L., a spin-off company founded and participated by J.R.G.M., ICIQ and ICREA.

\section{ACKNOWLEDGMENTS}

This work was supported by the European Union (projects ERC StG grant CHEMCOMP no. 279313 and Chem-fs-MOF no. 714122); the FEDER/Ministerio de Ciencia, Innovación y Universidades - Agencia Estatal de Investigación through the projects RTI2018-095618-B-100, CTP2016-80206-P, CTQ2017-89814-P, and CTQ2017-83486-P; the Generalitat de Catalunya (2017-SGR-1406); and the CERCA Programme/ Generalitat de Catalunya. S.R.G.B. also thanks MINECO for his predoctoral fellowship (BES-2014-067825 from CTQ201348396-P). We also thank the support of the National Science Foundation-CAREER grant (1352201). The research leading to these results has received funding from "La Caixa" Foundation. We thank C3UPO for the HPC support.

\section{REFERENCES}

(1) Batten, S. R.; Champness, N. R.; Chen, X.-M.; Garcia-Martinez, J.; Kitagawa, S.; Öhrström, L.; O'Keeffe, M. P.; Reedijk, J. Terminology of metal-organic frameworks and coordination polymers (IUPAC Recommendations 2013). Pure Appl. Chem. 2013, 85, 1715-1724.

(2) (a) Furukawa, H.; Cordova, K. E.; O'Keeffe, M.; Yaghi, O. M. The Chemistry and applications of metal-organic frameworks. Science 2013, 341, 1230444. (b) Slater, A. G.; Cooper, A. I. Function-led design of new porous materials. Science 2015, 348, No. aaa8075. (c) Islamoglu, T.; Goswami, S.; Li, Z. Y.; Howarth, A. J.; Farha, O. K.; Hupp, J. T. Postsynthetic tuning of metal-organic frameworks for targeted applications. Acc. Chem. Res. 2017, 50, 805-813.

(3) (a) Mason, J. A.; Oktawiec, J.; Taylor, M. K.; Hudson, M. R.; Rodriguez, J.; Bachman, J. E.; Gonzalez, M. I.; Cervellino, A.; Guagliardi, A.; Brown, C. M.; Llewellyn, P. L.; Masciocchi, N.; Long, J. R. Methane storage in flexible metal-organic frameworks with intrinsic thermal management. Nature 2015, 527, 357-361. (b) Cui, X.; Chen, K.; Xing, H.; Yang, Q.; Krishna, R.; Bao, Z.; Wu, H.; Zhou, W.; Dong, X.; Han, Y.; Li, B.; Ren, Q.; Zaworotko, M. J.; Chen, B. Pore chemistry and size control in hybrid porous materials for acetylene capture from ethylene. Science 2016, 353, 141-144. (c) Banerjee, R.; Phan, A.; Wang, B.; Knobler, C.; Furukawa, H.; O’Keeffe, M.; Yaghi, O. M. High-throughput synthesis of zeolitic imidazolate frameworks and application to CO2 capture. Science 2008, 319, 939-943.

(4) (a) Jagadeesh, R. V.; Murugesan, K.; Alshammari, A. S.; Neumann, H.; Pohl, M.-M.; Radnik, J.; Beller, M. MOF-derived cobalt nanoparticles catalyze a general synthesis of amines. Science 2017, 358, 326-332. (b) Zhao, M.; Yuan, K.; Wang, Y.; Li, G.; Guo, J.; Gu, L.; $\mathrm{Hu}$, W.; Zhao, H.; Tang, Z. Metal-organic frameworks as selectivity regulators for hydrogenation reactions. Nature 2016, 539, 76-80. (c) Xiao, D. J.; Bloch, E. D.; Mason, J. A.; Queen, W. L.; Hudson, M. R.; Planas, N.; Borycz, J.; Dzubak, A. L.; Verma, P.; Lee, K.; Bonino, F.; Crocellà, V.; Yano, J.; Bordiga, S.; Truhlar, D. G.; Gagliardi, L.; Brown, C. M.; Long, J. R. Oxidation of ethane to ethanol by $\mathrm{N}_{2} \mathrm{O}$ in a metalorganic framework with coordinatively unsaturated iron(II) sites. Nat. Chem. 2014, 6, 590-595.

(5) (a) Horcajada, P.; Chalati, T.; Serre, C.; Gillet, B.; Sebrie, C.; Baati, T.; Eubank, J. F.; Heurtaux, D.; Clayette, P.; Kreuz, C.; Chang, J. S.; Hwang, Y. K.; Marsaud, V.; Bories, P.-N.; Cynober, L.; Gil, S.; Férey, G.; Couvreur, P.; Gref, R. Porous metal-organic-framework nanoscale carriers as a potential platform for drug delivery and imaging. Nat. Mater. 2010, 9, 172-178. (b) Wu, M. X.; Yang, Y. W. Metal-organic framework (MOF)-based drug/cargo delivery and cancer therapy. $A d v$.
Mater. 2017, 29, 1606134. (c) Cai, W.; Chu, C. C.; Liu, G.; Wang, Y. X. Metal-organic framework-based nanomedicine platforms for drug delivery and molecular imaging. Small 2015, 11, 48064822.

(6) (a) Cadiau, A.; Adil, K.; Bhatt, P. M.; Belmabkhout, Y.; Eddaoudi, M. A metal-organic framework-based splitter for separating propylene from propane. Science 2016, 353, 137-140. (b) Herm, Z. R.; Bloch, E. D.; Long, J. R. Hydrocarbon separations in metal-organic frameworks. Chem. Mater. 2014, 26, 323-338. (c) Bloch, E. D.; Queen, W. L.; Krishna, R.; Zadrozny, J. M.; Brown, C. M.; Long, J. R. Hydrocarbon separations in a metal-organic framework with open iron(II) coordination sites. Science 2012, 335, 1606-1610. (d) Warren, J. E.; Perkins, C. G.; Jelfs, K. E.; Boldrin, P.; Chater, P. A.; Miller, G. J.; Manning, T. D.; Briggs, M. E.; Stylianou, K. C.; Claridge, J. B.; Rosseinsky, M. J. Shape selectivity by guest-driven restructuring of a porous material. Angew. Chem., Int. Ed. 2014, 53, 4592-4596. (e) Nugent, P.; Belmabkhout, Y.; Burd, S. D.; Cairns, A. J.; Luebke, R.; Forrest, K.; Pham, T.; Ma, S.; Space, B.; Wojtas, L.; Eddaoudi, M.; Zaworotko, M. J. Porous materials with optimal adsorption thermodynamics and kinetics for $\mathrm{CO}_{2}$ separation. Nature 2013, 495, 80-84. (f) Hartlieb, K. J.; Holcroft, J. M.; Moghadam, P. Z.; Vermeulen, N. A.; Algaradah, M. M.; Nassar, M. S.; Botros, Y. Y.; Snurr, R. Q.; Stoddart, J. F. CD-MOF: A versatile separation medium. J. Am. Chem. Soc. 2016, 138, 2292-2301. (g) Verma, P.; Xu, X. F.; Truhlar, D. G. Adsorption on Fe-MOF-74 for C1-C3 hydrocarbon separation. J. Phys. Chem. C 2013, 117, 12648-12660.

(7) Sun, B.; Kim, Y.; Wang, Y.; Wang, H.; Kim, J.; Liu, X.; Lee, M. Homochiral porous nanosheets for enantiomer sieving. Nat. Mater. 2018, 17, 599-604.

(8) Xie, R.; Chu, L.-Y.; Deng, J.-G. Membranes and membrane processes for chiral resolution. Chem. Soc. Rev. 2008, 37, 1243-1263.

(9) (a) Kutzscher, C.; Müller, P.; Raschke, S.; Kaskel, S. In The Chemistry of Metal-Organic Frameworks: Synthesis, Characterization, and Applications; Kaskel, S., Ed.; Wiley VCH Verlag GmbH \& Co.: New York, 2016; pp 387-419. (b) Duerinck, T.; Denayer, J. F. M. Metalorganic frameworks as stationary phases for chiral chromatographic and membrane separations. Chem. Eng. Sci. 2015, 124, 179-187. (c) Padmanaban, M.; Müller, P.; Lieder, C.; Gedrich, K.; Grünker, R.; Bon, V.; Senkovska, I.; Baumgärtner, S.; Opelt, S.; Paasch, S.; Brunner, E.; Glorius, F.; Klemm, E.; Kaskel, S. Application of a chiral metal-organic framework in enantioselective separation. Chem. Commun. 2011, 47, 12089-12091. (d) Das, S.; Xu, S.; Ben, T.; Qiu, $\mathrm{S}$. Chiral recognition and separation by chirality-enriched metal-organic frameworks. Angew. Chem., Int. Ed. 2018, 57, 8629-8633. (e) Wang, W.; Dong, X.; Nan, J.; Jin, W.; Hu, Z.; Chen, Y.; Jiang, J. A homochiral metal-organic framework membranes for enantioselective separation. Chem. Commun. 2012, 48, 7022-7024. (f) Bhattacharjee, S.; Khan, M. I.; Li, X.; Zhu, Q.; Wu, X. Recent progress in asymmetric catalysis and chromatogrsphic separation by chiral metal-organic frameworks. Catalysts 2018, 8, 120. (g) Zhang, M.; Pu, Z.; Chen, X.; Gong, X.; Zhu, A.; Yuan, L. Chiral recognition of a 3D chiral nanoporous metalorganic framework. Chem. Commun. 2013, 49, 5201-5203. (h) Zhang, M.; Xue, X.; Zhang, J.; Xie, S.; Zhang, Y.; Yuan, L. Enantioselective chromatographic resolution using a homochiral metal-organic framework in HPLC. Anal. Methods 2014, 6, 341-346. (i) Tanaka, K.; Hotta, N.; Nagase, S.; Yoza, K. Efficient HPLC enantiomer separation using a pillared homochiral metal-organic framework as a novel chiral stationary phase. New J. Chem. 2016, 40, 4891-4894.

(10) (a) Rabone, J.; Yue, Y.-F.; Chong, S. Y.; Stylianou, K. C.; Bacsa, J.; Bradshaw, D.; Darling, G. R.; Berry, N. G.; Khimyak, Y.Z.; Ganin, A. Y.; Wiper, P.; Claridge, J. B.; Rosseinsky, M. J. An adaptable peptide-based porous material. Science 2010, 329, 1053-1057. (b) Katsoulidis, A. P.; Park, K. S.; Antypov, D.; Martí-Gastaldo, C.; Miller, G. J.; Warren, J. E.; Robertson, C. M.; Blanc, F.; Darling, G. R.; Berry, N. G.; Purton, J. A.; Adams, D. J.; Rosseinsky, M. Guest-adaptable and water-stable peptidebased porous materials by imidazolate side chain control. Angew. Chem., Int. Ed. 2014, 53, 193-198.

(11) Navarro-Sánchez, J.; Argente-García, A. I.; Moliner-Martínez, Y.; Roca-Sanjuán, D.; Antypov, D.; Campíns-Falcó, P.; Rosseinsky, M. J.; Martí-Gastaldo, C. Peptide metal-organic frameworks for enantiose- 
lective separation of chiral drugs. J. Am. Chem. Soc. 2017, 139, 42944297.

(12) (a) Martí-Gastaldo, C.; Antypov, D.; Warren, J. E.; Briggs, M. E.; Chater, P. A.; Wiper, P. V.; Miller, G. J.; Khimyak, Y. Z.; Darling, G. R.; Berry, N. G.; Rosseinsky, M. J. Side-chain control of porosity closure in single-and multiple-peptide-based porous materials by cooperative folding. Nat. Chem. 2014, 6, 343-351. (b) Navarro-Sánchez, J.; MullorRuíz, I.; Popescu, C.; Santamaría-Pérez, D.; Segura, A.; Errandonea, D.; González-Platas, J.; Martí-Gastaldo, C. Peptide metal-organic frameworks under pressure: flexible linkers for cooperative compression. Dalton Trans 2018, 47, 10654-10659. (c) Marti-Gastaldo, C.; Warren, J. E.; Stylianou, K. C.; Flack, N. L. O.; Rosseinsky, M. J. Enhanced Stability in Rigid Peptide-Based Porous Materials. Angew. Chem., Int. Ed. 2012, 51, 11044-11048.

(13) (a) Gomez, V.; Lillo, V.; Escudero-Adan, E. C.; Martin, E.; Galan-Mascaros, J. R. Aqueous synthesis of sulfonate-functionalized 1,2,4-triazole ligands and their 2D Cd2+ coordination networks: crystal structure and photoluminescent properties. Dalton Trans 2013, 42, 6374-6380. (b) Mon, M.; Bruno, R.; Tiburcio, E.; Grau-Atienza, A.; Sepúlveda-Escribano, A.; Ramos-Fernandez, E. V.; Fuoco, A.; Esposito, E.; Monteleone, M.; Jansen, J. C.; Cano, J.; Ferrando-Soria, J.; Armentano, D.; Pardo, E. Efficient gas separation and transport mechanism in rare hemilabile metal-organic framework. Chem. Mater. 2019, 31, 5856. (c) Mon, M.; Ferrando-Soria, J.; Verdaguer, M.; Train, C.; Paillard, C.; Dkhill, B.; Versace, C.; Bruno, R.; Armentano, D.; Pardo, E. Postsynthetic approach for the rational design of chiral ferroelectric metal-organic frameworks. J. Am. Chem. Soc. 2017, 139, 8098-8101.

(14) Bartlett, R. K.; Humphrey, I. R. Transaminations of N,Ndimethylformamide azine. J. Chem. Soc. C 1967, 1664-1666.

(15) Lysenko, A. B.; Senchyk, G. A.; Domasevitch, K. V.; Kobaltz, M.; Krautscheid, H.; Cichos, J.; Karbowiak, M.; Neves, P.; Valente, A. A.; Gonçalves, I. S. Triazolyl, Imidazolyl, and Carboxylic Acid Moieties in the Design of Molybdenum Trioxide Hybrids: Photophysical and Catalytic Behavior. Inorg. Chem. 2017, 56, 4380-4394.

(16) Dubbeldam, D.; Torres-Knoop, A.; Walton, K. S. On the inner working of Monte Carlo codes. Mol. Simul. 2013, 39, 14-15.

(17) Mayo, S. L.; Olafson, B. D.; Goddard III, W. A. DREIDING: A generic force field for molecular simulations. J. Phys. Chem. 1990, 94, 8897-8909.

(18) Rappe, A. K.; Casewit, C. J.; Colwell, K. S.; Goddard, W. A.; Skiff, W. M. UFF, a full periodic table force field for molecular mechanics and molecular dynamics simulations. J. Am. Chem. Soc. 1992, 114, 1002410035.

(19) (a) Yazaydin, A. O.; Benin, A. I.; Faheem, S. A.; Jakubczak, P.; Low, J. J.; Willis, R. R.; Snurr, R. Q. Enhanced $\mathrm{CO}_{2}$ adsorption in metalorganic frameworks via occupation of open-metal sites by coordinated water molecules. Chem. Mater. 2009, 21, 1425-1430. (b) Greathouse, J. A.; Allendorf, M. D. The interaction of water with MOF-5 simulated by molecular dynamics. J. Am. Chem. Soc. 2006, 128, 10678-1067. (c) Karra, J. R.; Walton, K. S. Effect of open metal sites on adsorption of polar and nonpolar molecules in metal-organic framework Cu-BTC. Langmuir 2008, 24, 8620-8626. (d) Calero, S.; Gómez-Álvarez, P. Underlying adsorption mechanisms of water in hydrophobic and hydrophilic zeolite imidazolate frameworks: ZIF-71 and ZIF-90. J. Phys. Chem. C 2015, 119, 467-472. (e) Bae, Y.-S.; Lee, C. Y.; Kim, K. C.; Farha, O. K.; Nickias, P.; Hupp, J. T.; Nguyen, S. T.; Snurr, R. Q. High propene/propane selectivity in isostructural metal-organic frameworks with high densities of open metal sites. Angew. Chem., Int. Ed. 2012, 51, 1857-1860. (f) Vicent-Luna, J. M.; Gutiérrez-Sevillano, J. J.; Hamad, S.; Anta, J.; Calero, S. Role of ionic liquid $[\mathrm{EMIM}]^{+}[\mathrm{SCN}]^{-}$in the adsorption and diffusion of gases in metal-organic frameworks. ACS Appl. Mater. Interfaces 2018, 10, 29694-29704.

(20) Widom, B. Some Topics in the Theory of Fluids. J. Chem. Phys. 1963, 39, 2808-2812.

(21) Sheldrick, G. M. Crystal structure refinement with SHELXL. Acta Crystallogr., Sect. C: Struct. Chem. 2015, C71, 3-8.
(22) Hubschle, C. B.; Sheldrick, G. M.; Dittrich, B. ShelXle: a Qt graphical user interface for SHELXL. J. Appl. Crystallogr. 2011, 44, $1281-1284$.

(23) (a) Xia, Z.; Jing, X.; He, C.; Wang, X.; Duan, C. Coordinative alignment of chiral molecules to control over chirality transfer in spontaneous resolution and asymmetric catalysis. Sci. Rep. 2017, 7, 15418. (b) Tu, B.; Pang, Q.; Wu, D.; Song, Y.; Weng, L.; Li, Q. Ordered vacancies and their chemistry in metal-organic frameworks. J. Am. Chem. Soc. 2014, 136, 14465-14471. (c) Li, M.; Du, D.; Yang, G.; Li, S.; Lan, Y.; Shao, K.; Qin, J.; Su, Z. 3D chiral microporous (10,3)-a topology metal-organic framework containing large helical channels. Cryst. Growth Des. 2011, 11, 2510-2514. (d) Zhang, J.-P.; Kitagawa, S. Supramolecular Isomerism, Framework Flexibility, Unsaturated Metal Center, and Porous Property of $\mathrm{Ag}(\mathrm{I}) / \mathrm{Cu}(\mathrm{I}) 3,3^{\prime}, 5,5^{\prime}$-Tetrametyl-4,4'Bipyrazolate. J. Am. Chem. Soc. 2008, 130, 907-917.

(24) Wang, K.; Lv, X.-L.; Feng, D.; Li, J.; Chen, S.; Sun, J.; Song, L.; Xie, Y.; Li, J.-R.; Zhou, H.-C. Pyrazolate-Based Porphyrinic MetalOrganic Framework with Extraordinary Base-Resistance. J. Am. Chem. Soc. 2016, 138, 914-919.

(25) Demessence, A.; D’Alessandro, D. M.; Foo, M.-L.; Long, J. R. Strong $\mathrm{CO}_{2}$ binding in a water-stable, triazolate-bridged metal-organic framework functionalized with ethylenediamine. J. Am. Chem. Soc. 2009, 131, 8784-8786.

(26) Boneberg, E. M.; Zou, M. H.; Ullrich, V. Inhibition of cyclooxygenase- 1 and -2 by $\mathrm{R}(-)$ - and $\mathrm{S}(+)$-Ibuprofen. J. Clin. Pharmacol. 1996, 36, 16S-19S.

(27) (a) Reshalaiti, H. M.; Li, W.; Junzhang, Q.; Ruxin, Y.; Xian-Ming, Z.; Huwei, L. Planar Mn4O cluster homochiral metal-organic framework for HPLC separation of pharmaceutically important ( \pm )-Ibuprofen Racemate. Inorg. Chem. 2015, 54, 3713-3715. (b) Sheng-Ming, X.; Mei, Z.; Zhi-Xin, F.; Li-Ming, Y. Experimental comparison of chiral metal-organic framework used as stationary phase in chromatography. J. Chromatogr. A 2014, 1363, 137-143.

(28) Webster, G. K.; Szczerba, T. J. Supercritical fluid chromatography for chiral method development screening and analysis. In Supercritical Fluid Chromatography: Advances and Applications in Pharmaceutical Analysis; Webster, G. K., Ed.; CRC Press: New York, 2014.

(29) (a) van Erp, T.; Caremans, T.; Dubbeldam, D.; Martin Calvo, A.; Calero, S.; Martens, J. Enantioselective Adsorption in Achiral Zeolites. Angew. Chem., Int. Ed. 2010, 49, 3010-3013. (b) Caremans, T. P.; van Erp, T. S.; Dibbeldam, D.; Castillo, J. M.; Martens, J. A.; Calero, S. Enantioselective adsorption characteristics of aluminum-substituted MFI zeolites. Chem. Mater. 2010, 22, 4591-4601. (c) Bueno-Perez, R.; Martin-Calvo, A.; Gómez-Álvarez, P.; Gutiérrez-Sevillano, J. J.; Merkling, P. J.; Vlug, T. J. H.; van Erp, T. S.; Dubbeldam, D.; Calero, $S$. Enantioselective adsorption of ibuprofen and lysine in metal-organic frameworks. Chem. Commun. 2014, 50, 10849-19852. (d) BuenoPerez, R.; Balestra, S. R. G.; Camblor, M. A.; Min, J. G.; Hong, S. B.; Merkling, P. J.; Calero, S. Influence of flexibility on the separation of chiral isomers in STW-type zeolite. Chem. - Eur. J. 2018, 24, 4121.

(30) Widom, B. Some Topics in the Theory of Fluids. J. Chem. Phys. 1963, 39, 2808-2812.

(31) Bruno, R.; Marino, N.; Bartella, L.; Di Donna, L.; De Munno, G.; Pardo, E.; Armentano, D. Highly efficient temperature dependent chiral separation with a nucleotide-based coordination polymer. Chem. Commun. 2018, 54, 6356-6359.

(32) Addicoat, M. A.; Vankova, N.; Akter, I. F.; Heine, T. J. Extension of the universal force field to metal-organic frameworks. J. Chem. Theory Comput. 2014, 10, 880-891. 